\title{
Prognosis and Diagnosis of Farm Tractors Reliability and Availability for Maintenance Policies Using Markov - Chain Model
}

\author{
Omran Musa Abbas *, Hassan Ibrahim Mohammed \\ Department of Agricultural Engineering, College of Agricultural Studies, Sudan University of Science and Technology, Sudan
}

Copyright (C) 2015 by authors, all rights reserved. Authors agree that this article remains permanently open access under the terms of the Creative Commons Attribution License 4.0 International License

\begin{abstract}
A sound maintenance planning is of crucial importance for farm power systems. There is a large potential in cost savings by optimizing maintenance decisions to make utilization of farm tractors more cost-efficient. Reliability and availability are fundamental attributes of organization, scheduling and operation of fleet of tractors in agricultural project of multi-farms. This paper utilizes recursive Markov chain closed-form analytical solution and condition-based maintenance model to evaluate performance of degraded multi-state system. First state of system failure is inspected, analyzed, and classified into partial, or combined or complete failure of estimating the transition matrix for the failure state. At each inspection of failure status a preventive maintenance (minor repair by replacement of parts) or corrective maintenance (major replacement of parts by complete overhaul) is performed to restore the system to "as good as new". The development of condition-based maintenance is used to signify the monitoring of machines for the purpose of diagnostics and prognostics. Diagnostics are used to determine the current status of a machine's frequency of failure (useful life) and prognostics are used to predict its dependability, availability (utility).Hence, the system of evaluation is quantified by six distinct indicators (maximum time before failure, tractor dependability, availability, frequency of failure and operating time between preventive and corrective maintenance) such that appropriate actions can be planned and taken in order to minimize the impact of equipment failure to operation. Simulation results for a dataset of three tractors (T120, C225 and B250) from two workshops of sugar plantation (Gunied and Sennar factories in Sudan) is investigated to assert the magnitude of variation between the tested variables that justify changing current maintenance policy using analysis of variation. The results indicate the applicability of Markov where comparison with condition-based maintenance is the optimal maintenance strategy for tractor high failure rate.
\end{abstract}

Keywords Markov-chain Process, Reliability, Availability, Maintenance Strategies, Time-Based Schedule, Tractor Fault Diagnosis

\section{Introduction}

Worldwide agricultural projects with smallholder farms are assumed to be effective instrument to develop rural areas. Tractors which is the main source of power in these farms, if properly and given the necessary field maintenance will operate for long period and do a great deal of work before major repairs are required.[8]

Sudan has three distinct farming systems, these are: irrigated, mechanized rain-fed and traditional rain-fed sub-sectors. The irrigated agriculture accounted for an average of about $21 \%$ of the value of total agricultural, irrigated farming has been one of the pillars of agricultural development strategy. This sector is dominated by large national schemes like Gezira, New Halfa, Rahad and Sugar schemes. The Mechanized Rain-fed Sub-Sector concentrated in Gadara, White Nile, Sinnar, and Southern Kordofan states. Mechanized farming accounts for about $65 \%$ of the sorghum, $53 \%$ of the sesame, $5 \%$ of the millet, and almost $100 \%$ of sunflower produced in Sudan. Traditional rain-fed sub-sectors includes nomadic, transhumance (moving with livestock and growing short-maturity subsistence crops), and sedentary agriculture which also includes a significant number of livestock. [1]

Maintenance method is an algorithm of procedures which aim at producing the conditions which will enable technical systems to reach certain goals. It is also expected to be able to predict production downtimes. Maintenance is often considered a separate and independent. [12]

Reliability is the probability that a system will perform satisfactorily for at least a given period of time when used under stated conditions. Maintenance Reliability covers those activities that are undertaken to keep the system operational or restore it to operational condition after a failure occurrence. The increase in equipment availability means higher productivity and thus higher profitability provided that the maintenance optimization does include the 
cost factor. This has lead to increase research interest in the subject of optimizing maintenance management. It is estimated that $15 \%$ to $45 \%$ of total production cost are attributed to maintenance cost with $30 \%$ of total manpower involvement [6]. The maintenance's high cost and low efficiency is one of the last costs saving frontier for companies to improve profitability. [12] Traditionally, reliability analysis of repairable system depends upon the assumption that the system can be in need of a binary state; either need minor repair by replacement of fast moving parts or major replacement of parts by complete overhaul. With the assumption, numerous approaches, methodologies and models have emerged to predict the reliability of repairable systems corresponding to different repair assumptions. The models include variations of perfect renewals process which assumes perfect repair and normal distribution for minimal repair assumption as discussed in literatures including [5], [1] and [12]. Present research will be focusing on applying Markov process to farm tractors subject to failure. Markov process was chosen to model the system due to its versatility which can be used to describe mathematically performance of different maintenance management condition. The term condition-based maintenance (CBM) is used in this study to signify the monitoring of tractor for the purpose of diagnostics and prognostics. Diagnostics are used to determine the current status of a machine's frequency of failure (useful life) and prognostics are used to predict dependability, availability (Serviceability). CBM has the potential to greatly reduce costs by helping to avoid catastrophic failures (Engine overhaul which is extremely important point) and by more efficiently determining the intervals required for maintenance schedules [4].This is in particular is achieved via estimation of six performance indicators.

The main objective of this study is to offer a two-step Prognosis and diagnosis procedure: Failure prediction followed by evaluation of maintenance policy. The potential of the proposed methods is to be evaluated by a case-study where failures of three medium tractors in use in two sugar plantations are to be predicted. The procedure shall include a set of indicators for evaluating performance of the existing maintenance methods fitting the proposed approach.

\section{Materials \& Methods}

Model Development: the model to be applied is conducted by [12], this model validated and tested according to Amari and McLaughlin model [2].

Study Area: This study was carried out firstly in Guneid Sugar factory workshop was the first unit to come into existence in the year 1962. The initial goal in starting such unit was to meet the local sugar demand, reduce import of white sugar and thereby reduce foreign exchange load on the exchequer. In this scheme there is one main workshop and some of sub-main workshops which are involved in the maintenance and repairs of agricultural tractors. Secondly in Sennar Sugar factory workshop as like Guneid Sugar factory workshop manages by Sudanese Sugar Company. From the general descriptions of the two factory workshops given above, it is evident that there were some different between two workshops, namely the required number of different shops and responsible for maintaining all trucks which pull the cane trailers and preparing the soil for planting the canes on field or mobile shops. The management of workshops of Sennar followed especial strategies to keep record of using spar part for all tractors and other trucks. Moreover management of workshops carries out the check of all moving machineries besides setting a program for their maintenance (engine oil change spare parts) it has to report monthly about the condition of the machineries to the agricultural workshop.

Data collection: For the purpose of studying and analyzing tractor failure, maintenance recorded data were identified as paramount. These required data are as follows; Information relating to the number of failures of tractor parts during season for selected tractor, Information relating to actual tractor operating hours and the downtime for repair, Information relating to the type of failure (partial or combined or complete). Usually partial failure has short downtime while combined and complete has long downtime and Information relating to tractor working type (as land preparation, crop growing service and harvesting).To collect the above mentioned information data for these sizes of wheel tractors (80-120hp, 120-200hp and over 200hp) much effort was done to revise and validate the data which obtained from workshop headquarter and minor workshop of blocks of two factories farms.

Data analysis: Before collecting the final data a small sample data from three tractors of each model was made. This preparatory exercise is made to test the quality of data to be collected and to visualize and evaluate the generated result. Preparing the failure event data for analysis before collecting the final data provided some evidences both in terms of what data to record as well as how to record the information. For example, the time taken to repair failures was not recorded contemporaneously with the failure. This meant that technicians were required to estimate repair times after the fact, a time-consuming process after the event but information that would have taken seconds to record at the time as shown on table1. 
Table 1. Average Model Data of Three Tractors Samples (for Year 2004, 2005 and 2006) Gunied and Sennar Factory Workshop

\begin{tabular}{|c|c|c|c|c|c|c|c|c|c|c|}
\hline \multirow[b]{2}{*}{ Work shop } & \multirow[b]{2}{*}{ Year } & \multicolumn{3}{|c|}{ T120 } & \multicolumn{3}{|c|}{$\mathrm{C225}$} & \multicolumn{3}{|c|}{ B250 } \\
\hline & & $\begin{array}{c}\text { Working } \\
\text { Hours }\end{array}$ & $\begin{array}{l}\text { Av No of } \\
\text { failure }\end{array}$ & $\begin{array}{c}\text { Downtime } \\
\text { (hrs) }\end{array}$ & $\begin{array}{c}\text { Working } \\
\text { Hours }\end{array}$ & $\begin{array}{l}\text { Av No of } \\
\text { failure }\end{array}$ & $\begin{array}{l}\text { Downtime } \\
\text { (hrs) }\end{array}$ & $\begin{array}{c}\text { Working } \\
\text { Hours }\end{array}$ & $\begin{array}{l}\text { Av No of } \\
\text { failure }\end{array}$ & $\begin{array}{l}\text { Downtime } \\
\text { (hrs) }\end{array}$ \\
\hline \multirow{3}{*}{ Gunied } & 2004 & 450 & 17 & 40 & 462 & 17 & 54 & 495 & 28 & 74 \\
\hline & 2005 & 594 & 41 & 96 & 552 & 23 & 42 & 433 & 19 & 57 \\
\hline & 2006 & 578 & 37 & 56 & 484 & 61 & 105 & 630 & 28 & 49 \\
\hline \multirow{3}{*}{ Sennar } & 2004 & 556 & 31 & 42 & 549 & 29 & 54 & 326 & 25 & 43 \\
\hline & 2005 & 496 & 25 & 64 & 662 & 38 & 84 & 511 & 32 & 63 \\
\hline & 2006 & 453 & 45 & 69 & 519 & 46 & 85 & 707 & 37 & 64 \\
\hline
\end{tabular}

Table2. Average of Maximum Time before Failures of Two Wheel Tractors (T120, B250 and C225) for Gunied and Sennar Workshops factory

\begin{tabular}{|c|c|c|c|c|c|c|c|c|c|c|c|c|}
\hline MonthTractor & Jan. & $\mathbf{2}$ & $\mathbf{3}$ & $\mathbf{4}$ & $\mathbf{5}$ & $\mathbf{6}$ & $\mathbf{7}$ & $\mathbf{8}$ & $\mathbf{9}$ & $\mathbf{1 0}$ & $\mathbf{1 1}$ & $\mathbf{1 2}$ \\
\hline T120 & 130 & 130 & 86 & 98 & 113 & 95 & 71 & 60 & 75 & 81 & 130 & 108 \\
\hline B250 & 115 & 108 & 83 & 87 & 89 & 81 & 81 & 82 & 84 & 190 & 149 & 120 \\
\hline C225 & 203 & 211 & 137 & 205 & 170 & 175 & 160 & 148 & 110 & 79 & 110 & 130 \\
\hline
\end{tabular}

\section{Results \& Discussion}

The failure analysis maintenance management model is run using three tractors data (T120, C225 and B250) collected from two study sites (Gunied factory workshop and Sennar factory workshop). The purpose is to investigate and evaluate performance of the studied tractors with respect to the stander of maintenance in these two workshops using three proxy indicators (maximum time before failure, tractor dependability and frequency of failure),improvement of machinery programming with reference to availability concept and finally development of machinery maintenance scheduling program.

Performance of existing maintenance system:

The main indicators used in this study to evaluate level of performance of actually executed maintenance and the need of the studied tractors for either preventive or corrective maintenance is planned to be made by evaluating three parameters: maximum time before failure, tractor dependability, and frequency of occurrence of failure. These parameters are selected in accordance with [7] and [10]. The selection of the said parameter is oriented to be in line with quantitative outputs that can be generated as model outputs and reflect model behavior, and more important the system used for machinery maintenance in the Sudanese Sugar Company. As will be detailed latter in this discussion there is strong interlink before the selected performance parameters, the type of maintenance to follow (corrective or preventive) and management of maintenance in relation to machinery use in the field. Consequently, these indicators are viewed as abstract representation of the existing system. It is usually assumed that the required maintenance level is reflected in tractor maximum time before failure (available time free of defects) occurs, so to improve level of mechanized field operation, less tractor downtime and long working period at time of tractor peak demand, that on line with Barbera. [3]

T120 wheel Tractor: The period from July to month October is the lowest time before failure, as shown figure 1, the maximum time before failure is 130 hour and coincide with the period of peak frequency failure .In contrast July is the month of the lowest operating time before corrective maintenance. It is evident from the data of figure 1 and table 2 that in this same month (July) corrective maintenance started to improve and the time start slowly creeping. On the other hand the preventive maintenance sequence has same trend but with very slowly creeping as daily preventive maintenance.

B250 wheel tractor: As given in figure 1 and table 2, the maximum time before failure of this tractor is 190 hour at time of start of heavy field operations for crop harvesting (October) and it continues with slight decrease to a value of 108 hours in February which lies within the time of heavy work load. In actual practice as seen in figure 1 and table 2 the period of month July and August is the period for corrective maintenance where the operating time before corrective maintenance actually increases. Recall that this is the period of least field work and maximum maintenance work load, so the rate of change of operating time of preventive maintenance is almost similar and coincides with the period of heavy field work.

C225 wheel tractor: Figure 1 and Table 2 shows that the maximum time before failure is in the period of June to October and starts to drop from 175 hours (in June) to 79 hours (in October).Recall that at this time preventive maintenance at its lowest level. An overall look to same figure and table shows that the behavior of each individual tractor is unique and depends on tractor individual history (working hours, actual quality of maintenance and quality control measures). If we compare time of peak field work and time actually used for seasonal maintenance figures 1 and table 2 lindicate that it is possible to shorten time before preventive maintenance in order to increase time before failure for purpose of availing more time for field work at the critical time of peak field work load. However, to run such exercise cost component need to be considered for each individual case. 


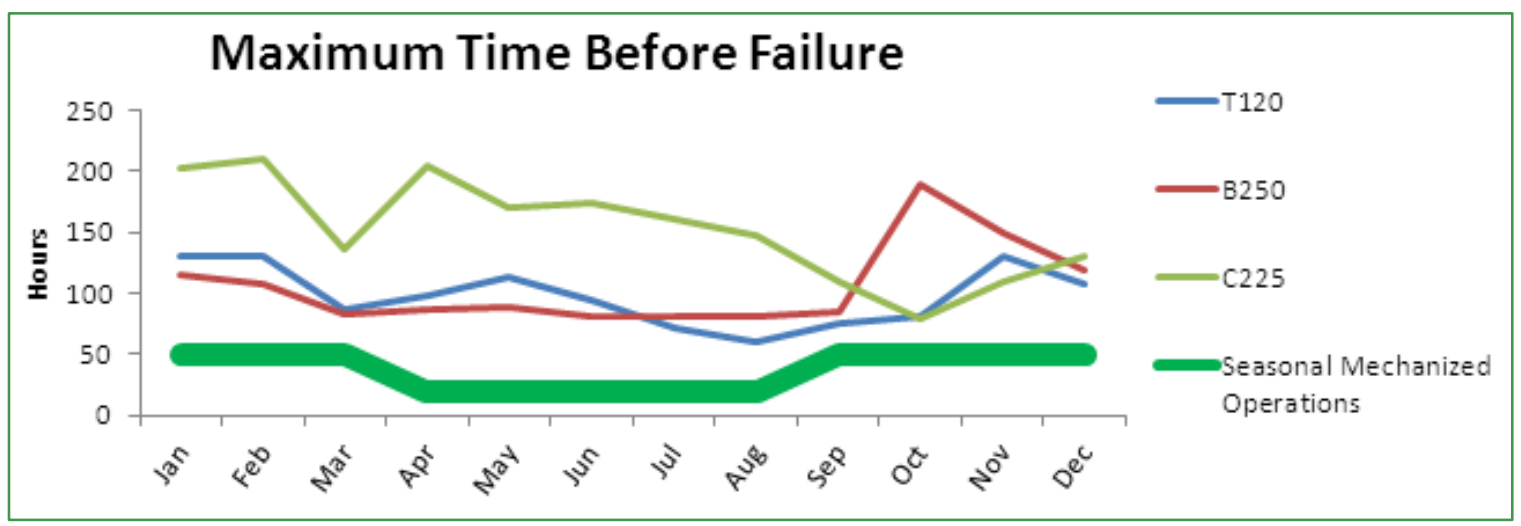

Figure 1. Average of Maximum Time before Failures of Wheel Tractors (T120, B250 and C225) for Gunied and Sennar factory

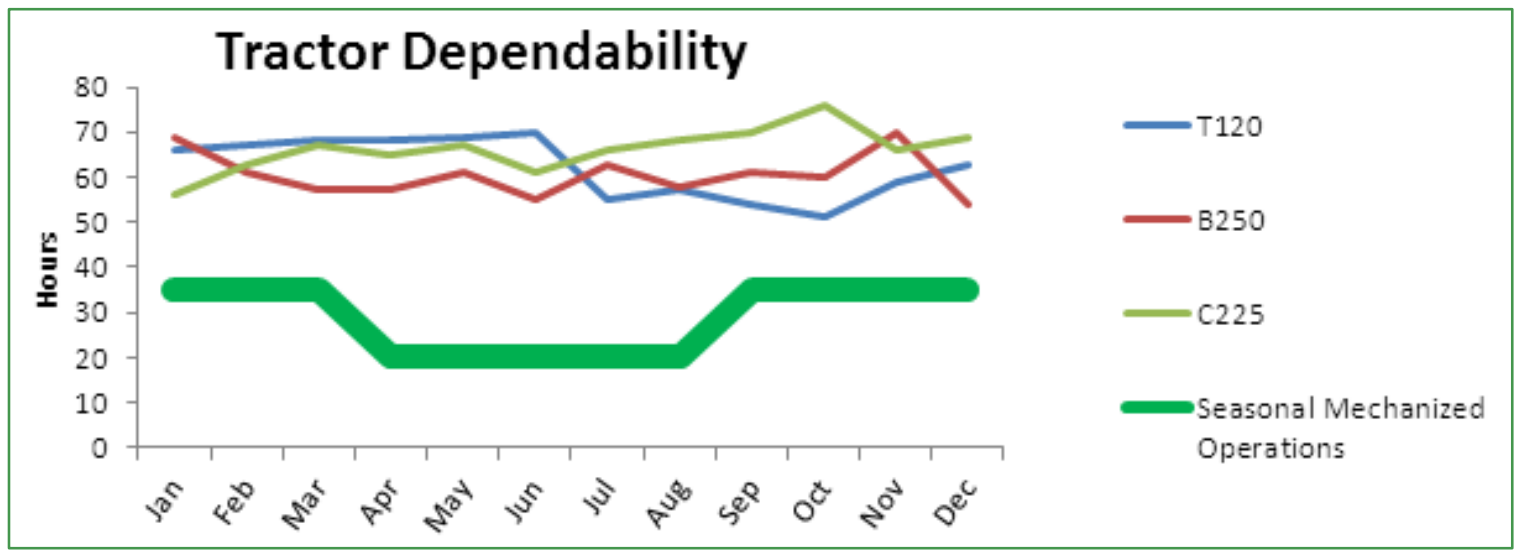

Figure2. Tractor Dependability of Wheel Tractor (B250 tractor, T120 tractor and C225 tractor) for Gunied and Sennar factory Workshop

Table3.Tractor Dependability of Wheel Tractor (B250 tractor, T120 tractor and C225 tractor) for Gunied and Sennar factory Workshop Model

\begin{tabular}{|c|c|c|c|c|c|c|c|c|c|c|c|c|}
\hline MonthTractor & $\mathbf{1}$ & $\mathbf{2}$ & $\mathbf{3}$ & $\mathbf{4}$ & $\mathbf{5}$ & $\mathbf{6}$ & $\mathbf{7}$ & $\mathbf{8}$ & $\mathbf{9}$ & $\mathbf{1 0}$ & $\mathbf{1 1}$ & $\mathbf{1 2}$ \\
\hline T120 & 66 & 67 & 68 & 68 & 69 & 70 & 55 & 57 & 54 & 51 & 59 & 63 \\
\hline B250 & 69 & 61 & 57 & 57 & 61 & 55 & 63 & 58 & 61 & 60 & 70 & 54 \\
\hline $\mathbf{C 2 2 5}$ & 56 & 63 & 67 & 65 & 67 & 61 & 66 & 68 & 70 & 76 & 66 & 69 \\
\hline
\end{tabular}

Analysis according to Tractor Dependability:

T120 wheel Tractor: Figur2 and table 3 shows that dependability in percentage as performance indicator is low and amounts to $55 \%$ in the period July to November (3-months). Recall that during this period field work is at its lowest intensity. In actual conditions at this period the time before preventive maintenance starts to increase indicating that the number of preventive maintenance executed in the workshop actually is few and the tractor is not given the support to re-generate its strength and power. This fact is supported by the increase in need for corrective maintenance. However, dependability starts rising steadily at a constant rate to a peak value of $70 \%$ in the period from October to July (period of maximum field work load) indicator which is on same line with Sullivan, (2004).
B250 wheel tractor: Figur2 and table 3 indicate that maximum dependability is $70 \%$ and the minimum one is $55 \%$. The lowest value coincides with the period usually planned for seasonal heavy maintenance (period of lowest field work load), at this time the corrective maintenance increases to its peak level at the month of August.

C225 wheel tractor: Dependability value is in the range of 56 to $68 \%$ in months of January to August (Figure 2 and table 3).It may be deduced that the dependability value scored by this tractor in the said period is the lowest level achieved as compared to the other studied two tractors. However, dependability starts from this lower value of $58 \%$ scored in August to reach a higher value of $76 \%$ in October due to increase in corrective maintenance. 
Table4. Average of Failure Frequency of Wheel Tractor (B250 tractor, T120 tractor and C225 tractor ) for Gunied factory Workshop

\begin{tabular}{|c|c|c|c|c|c|c|c|c|c|c|c|c|}
\hline $\begin{array}{c}\text { Month } \\
\text { Tractor }\end{array}$ & $\mathbf{1}$ & $\mathbf{2}$ & $\mathbf{3}$ & $\mathbf{4}$ & $\mathbf{5}$ & $\mathbf{6}$ & $\mathbf{7}$ & $\mathbf{8}$ & $\mathbf{9}$ & $\mathbf{1 0}$ & $\mathbf{1 1}$ & $\mathbf{1 2}$ \\
\hline T120 & 0.010 & 0.008 & 0.006 & 0.006 & 0.005 & 0.004 & 0.003 & 0.003 & 0.009 & 0.004 & 0.004 & 0.003 \\
\hline B250 & 0.005 & 0.009 & 0.006 & 0.007 & 0.005 & 0.006 & 0.005 & 0.006 & 0.007 & 0.008 & 0.007 & 0.005 \\
\hline C225 & 0.005 & 0.007 & 0.003 & 0.002 & 0.004 & 0.006 & 0.008 & 0.009 & 0.008 & 0.008 & 0.009 & 0.007 \\
\hline
\end{tabular}

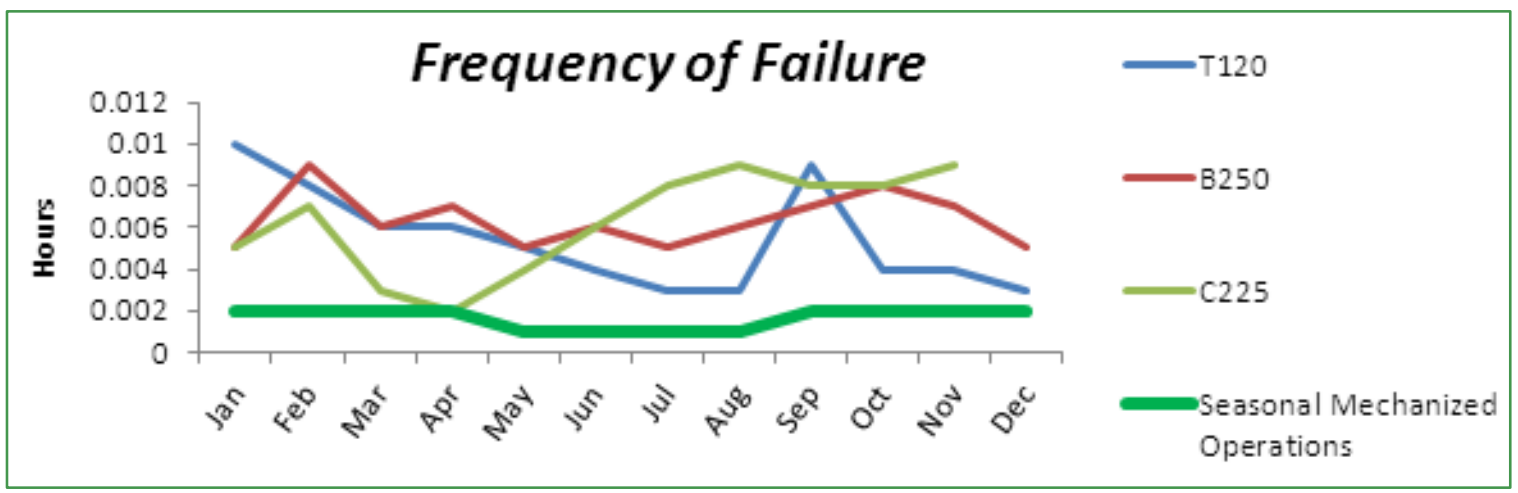

Figure3. Average of Failure Frequency of Wheel Tractor (B250 tractor, T120 tractor and C225 tractor) for Gunied factory Workshop

Analysis according to Frequency of Failure:

T120 wheel Tractor: Figure 3 and table 4 shows two peaks of maximum frequency of failure (at months of February and September). Months of June, July and august are of lowest field work load and at the same time shows lowest frequency of failure. Hence, failure frequency is linked with heavy field use or misuse. The figure confirms the fact that frequency is decreasing with work decrease in period from February to July and similar trend is followed by both preventive maintenance and corrective maintenance. This result is in agreement with the trend line of maximum time before failure.

B250 wheel tractor: The frequency of failure as given Figure 3 and table 4 starts to slightly increase from July to October (The peak is at November). The trend is similar to that of both preventive maintenance and corrective maintenance. This may refer to inadequate maintenance and to shorten the time before preventive maintenance. Reading figure 3 and table 4 together it is possible to deduce that: the frequency of failure in general is in contrast to the maximum time before failure.

C225 wheel tractor: As given in figure 3 the frequency of failure is high at time of peak field work and decrease at time of low one. Similar trend is followed by both preventive maintenance and corrective maintenance.

\section{Conclusions and Recommendations}

The utilization of the failure analysis model as experimental tool to evaluate impacts of three working status (variables: workshop type, tractor model and working season) for maintenance management and operating time between conducting preventive and corrective maintenance forms reveals that: for maximum time before failure: B250 tractor of Gunied superseded other two tractors while T120 tractor is not seriously affected by variation of level of maintenance services. For tractor dependability: tractors are ranked in descending order by Duncan test into T120 tractor of Gunied is first, secondly is B250 of Gunied and finally is C225 tractor of Gunied according to tractor dependability. For frequency of failure: the order of variation of factors is ranked in descending manner as T120 tractor and C225 tractor of Gunied is first and second respectively, finally is B250 of Sennar. For tractor availability: the variation in tractor models is ranked in descending order as B250 tractor of Gunied is first, secondly is T120 tractor of Sennar and finally is C225 tractor of Sennar according to tractor availability. For operating time between preventive maintenance: the order of variation between factors models is descending as C225 tractor is first, second is T120 tractor and last one B250 tractor, and corrective maintenance the order of variation for the studied factors indicate that all tractors of Sennar as T120 tractor is first, secondly is C225 tractor of Gunied and finally B250 tractor according to corrective maintenance.

The second step involves analysis of impacts of tractor performance indicators of availability and dependability on maximum time before failure. Taking $50 \%$ chance of dependability of time before failure B250 tractor tractors of Sennar is the most dependable, while B250 tractor of Gunied is the least dependable reflecting the variation of maintenance level between the two workshops. The order of other tractors in descending manner is that B250 tractor of Sennar is followed by T120 tractor -Gunied then B250 tractor -Gunied. The response curve of the impacts of 50\% chance availability of tractors on maximum time before failure reveals the order of significant factors impact in descending manner is ranked as T120 tractor-Gunied, B250 tractor -Sennar and B250 tractor Gunied. Step two analysis 
shows that a B250 tractor of Sennar is best with respect to time before failure while T120 tractor. Gunied is best with respect to time before failure. This indicates that the type of tractor to select depends on standard of maintenance in the workshop.

The improvement of machinery field scheduling program through the combined effects of machine reliability and time lines (machine availability) is based on the assumption that past historical behavior the highly to occur in future under similar machinery management condition. Tractor availability is found to be around $50 \%$ and the reliable number of tractor needed to execute field operation time of peak demand in Sudanese company sugar cane farms in 58 tractors in steady of using the current risky number with unpredicted failure of 38 tractors. Availability factor of 0.9 is recommended adjusting number of tractors needed to exact farm operation.

Instead of using the static machinery maintenance scheduling performance recommended under ideal design conditions, the failure model predicate alternative dynamic and more real maintenance policy scheduling program as; Selection of suitable tractor type needs to be made with relation to availability quality of maintenance (Workshop quality). B250 tractor proved to be the most suitable tractor for Sennar condition while T120 tractor is most performance under Gunied condition. The model can used to estimate tractor availability factor for adjusting scheduling program for executing mechanized cultural practices. For sugar cane of Sudanese company availability factor of $90 \%$ is recommended. As alternative to the manufacturer maintenance schedule the developed model is recommended to be used to predict a real and practical program. Analysis of the model may be extended in future to include an additional subroutine for each individual subsystem of the tractors. The developed model need to be used for analysis of tractors in the case of un- predictable machinery working days of rain fed crop production. To develop effective machinery management system and sound maintenance polices it is essential to give more emphasis to improve record system and maintenance tractors log-book and use electronic and computer facilities.

\section{REFERENCES}

[1] Abd Elkraim, A.F 2001 evaluation of sugarcane losses, $\mathrm{PhD}$ unpublished Thesis University of Gezirea - Faculty of Agricultural Science.

[2] Amari and McLaughlin, Suprasad V. Amari, An Analytical Model for the Optimization of Maintenance profitability. International Journal of Productivity and Performance
Management (54): 113-134.2004 Ph.D., Relex Software Corporation, Greensburg0-7803-8215-3/04/\$17.00 (C) 2004 IEEE Relex Software Corporation 540 Pellis Road Greensburg, PA 15601 USA.

[3] Barbera, ,Fran, Helmut Schneider, Ed Watson1999,A condition based maintenance model for a two-unit series system Department of Information Systems and Decision Sciences, Louisiana State University, Baton Rouge, LA 70803, USA.

[4] Bunks, c. ,Mccarthy , D., and Tarik al-ani 2000 Condition-based maintenance of machines using hidden Markov models. Mechanical Systems and Signal Processing (2000) 14(4), 597\}612.

[5] Chang, S. V. Amari, and S.-Y. Kuo, "Computing System Failure Frequencies and Reliability Importance Measures Using OBDD," IEEE Trans. Computers, vol. 53, pp. 54-68, January 2004.

[6] De Castro H. F., Cavalca K. L. (2006) Maintenance resources optimization applied to a manufacturing system. Reliability Engineering and System Safety 2006, 91:413-420.

[7] Desai. F, Richard .W.R 2006. Minimal inspection strategies for single unit systems. Naval Research Logistics Quarterly (28): 375-381.USA.

[8] Elbashir, Ali Hammed, 1996 Tillage for sugar cane in Sudan with special reference to Kenana, PhD Thesis, 1996 university of Khartoum, faculty of agricultural. http://www.unsudanig.org/sector/index.php.

[9] Ireson W. G., Coombs C. F., Moss R. Y. (1996) Handbook of reliability engineering and management. McGraw-Hill Professional, New York, USA, 1996

[10] Ishola, A 2004 study of farm tractors reliability in Kwara state of Nigeria. Control Engineering Journal,

[11] Kuo W., Zuo M. J. (2003). Optimal reliability modeling: Principles and Applications. John Wiley \& Sons, Hoboken, New Jersey, USA, 2003.

[12] Musa Omran Abbas and Hassan Ibrahim Mohhmed, 2009 development and application predictive markov-chain condition- based tractor maintenance management model $\mathrm{PhD}$ unpublished thesis Sudan University of science and technology Faculty of Agricultural studies.

[13] Robert Grisso, 2000 the kernel-adatron algorithm: A fast and simple learning procedure for support vector machines Extension Engineer, Biological Systems Engineering Eastern Virginia Agricultural Research and Extension Center.

[14] Saad Eldin, Ibrahim Iaz Eldin 2006, Third National Report on the Implementation of The Convention on Biological DiversityKhartoum, Sudan Higher Council for Environment Natural Recourses .

[15] Sullivan D.E, 2004 Operations \& Maintenance; Best Practices; A Guide to Achieving Operational Efficiency G. P. Northwest National Laboratory for the Federal Energy Management Program U.S. Department of Energy. 